\section{O fascismo e o populismo entre a história global e a teoria política}

FINCHELSTEIN, Federico. Do fascismo ao populismo na história. Lisboa: Edições 70, 2019.

Alexandre Douglas Zaidan de Carvalho (https://orcid.org/0000-0001-8366-9006)' Universidade Católica do Salvador, Salvador, BA, Brasil. Maurício Palma (https://orcid.org/0000-0002-5985-5287)" Universidade de Brasília, Brasília, DF, Brasil.

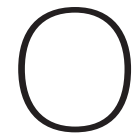
desafio interdisciplinar de propor um diálogo entre a teoria política e a historiografia é central na formulação metodológica de Federico Finchelstein em Do fascismo ao populismo na história. Nele, a discussão conceitual e os efeitos políticos da compreensão do fascismo e do populismo são articulados historicamente aos seus contextos de origem, apresentando seus desenvolvimentos locais e transnacionais. Essa preocupação se reflete no principal argumento do livro, que demonstra como o atual avanço de governos populistas no plano global deriva, em grande medida, da reformulação do fascismo nas democracias do pós-Guerra.

O fascismo e o populismo são descritos a partir de uma abordagem menos eurocêntrica e mais cosmopolita ou transatlântica. Perón é tido como o primeiro populista moderno, por exemplo. Para Finchelstein, lançar os olhos às fontes do passado e para a diversidade de regimes populistas, especialmente na América Latina, mas também na Ásia e na África, ajudaria cientistas políticos do Norte global a explicar fenômenos como o trumpismo, o bolsonarismo, Erdoğan, Salvini e Orbán. A convergência da história política e intelectual do fascismo e do populismo é destacada como forma de deixar mais clara a própria distinção entre ambos e suas formas de oposição à democracia. Em que pese tal proposta, os populismos latino-americanos e, fundamentalmente, o argentino são analisados mais detidamente. Casos africanos ou asiáticos não são aprofundados.

A obra possui três capítulos. O primeiro discute as origens do fascismo na Europa, destacando seu surgimento na Itália e sua radicalização violenta na Alemanha nazista, localizando-o historicamente como ideologia nacionalista contrarrevolucionária
Recebido: 26.07.20 Aprovado: 06.08.20

I. Alexandre Douglas Zaidan de Carvalho é professor do Programa de Pós-Graduação em Direito da Universidade Católica do Salvador (UCSal), Bahia, Brasil. <douglas.zaidan@ pro.ucsal.br>.

II. Maurício Palma é doutor em direito, Estado e Constituição pela Universidade de Brasília (UnB), DF, Brasil.

<mauriciopalma@ unb.br>. 
em relação às noções iluministas de liberdade e igualdade político-econômica que se expressavam nas democracias liberais e no socialismo real. O segundo explora o conceito de populismo em diversos contextos históricos, mas orientados pela derivação de formas fascistas rearticuladas em reação ao liberalismo e ativadas pela crise de representatividade no pós-1945, que mobilizou formas antiliberais e intolerantes de democracia. O terceiro analisa o populismo como categoria e regime político híbrido aglutinador de elementos democráticos e ditatoriais, descrevendo diferentes tipos de populismo de direita e esquerda e suas aproximações ao neoliberalismo. No epílogo, é discutido o regresso do populismo como fenômeno global liderado pelos Estados Unidos de Trump. No "Prefácio" à edição portuguesa, de janeiro de 2019, é debatido o avanço do trumpismo, negando-o como arquétipo histórico. A vitória de Bolsonaro, o "obcecado pela diferença sexual" (p. 20), é citada. Bolsonaro seria populista, racista e misógino e aproximaria fascismo e populismo.

Metodologicamente, a obra foca nas ideologias do fascismo e do populismo. Para defini-los, Finchelstein os reconstrói a partir da história política que os cerca, mas parte de que ambos supõem a rejeição moral do status quo da democracia liberal mobilizada por uma reação popular incorporada por líderes em oposição às elites e ao sistema político convencional. O fascismo e o populismo não se reduziriam às suas experiências e contingências territoriais, e a teoria política deveria observar mudanças e permanências que marcam o tempo e os usos do vocabulário político próprio dos fenômenos.

Objetiva-se avaliar equívocos conceituais de análises recentes do populismo, as quais que mesclariam anacronicamente elementos de regimes populistas, confundindo estes com a social-democracia, ditaduras e até com programas progressistas, quando tomadas pelo grau de participação cívica da população. Por isso, distingue o fascismo do populismo, demonstrando em diversas passagens (p. 37, 50, 59, 77, $109,123,139,166,193,196,207,210,232$ e 246) que o segundo é uma adaptação do primeiro, condicionado pela democracia do pós-Guerra, resultante da derrota fascista. A repetição desse ponto, aliás, é exagerada e torna maçante a leitura. A compreensão a-histórica dos significados potencializaria o uso deslocado do termo "fascista" para designar populista. Essa distinção permite que o autor afirme que "como regime, o fascismo nunca voltou depois do fim da Segunda Guerra Mundial, e, com efeito, a ausência de regimes fascistas definiu a segunda metade do século passado" (p. 44), assim como, após 1945, poucos políticos abraçaram abertamente o fascismo, mesmo adotando-o como teoria e prática políticas.

Em trabalho anterior (Finchelstein, 2010) Finchelstein apresenta o fascismo como ideologia mítica transnacional com especificações nacionais relevantes. Desde o seu início no norte da Itália, em 1919, o fascismo se autoproclamava ideologia glo- 
bal (Finchelstein, 2010: 10) e recorreu à noção imperialista universal do então nacionalismo italiano. Para Mussolini, bem como para fascistas italianos, as ideias teriam utilidade enquanto legitimassem os objetivos políticos definidos por seu líder messiânico. Entre suas metas estavam o nacionalismo extremo, a militarização da política, o racismo, a aspiração totalitária, a perseguição e o exercício da violência contra um inimigo. O fascismo se apresentou como alternativa ao liberalismo e ao socialismo, propondo organizar o capitalismo segundo uma ordem corporativista.

O fascismo usaria da violência de forma diferente em relação a outros projetos autoritários concorrentes. No fascismo, o primado da violência deixa de ser um meio e torna-se um fim político em si mesmo, como mostra o Holocausto (p. 77 e 95ss). Ao exemplificar a entropia nazista em torno da violência na decisão de Hitler em contrariar a lógica militar ao sacrificar suas tropas no Leste e direcioná-las à solução final antissemita, o autor afirma que o "fascismo termina quando alcança o seu imperativo ideologicamente sagrado da violência" (p. 96). O funcionamento do aparato violento, no entanto, depende de sua representação transcendental na esfera do sagrado, pois justificada por uma mitologia política, fenômeno que se mundializou. A crença no líder como ato de fé fez do fascismo uma "religião política" (p. 103), o que dispensava o regime de responder empiricamente sobre as suas ações e falhas, liberando-se da responsabilidade política, diferentemente do liberalismo e do socialismo.

O fascismo possuiria caráter imperialista. Inspirado no expansionismo colonial do Império Romano, o fascismo italiano exprimiu na ideia de força sua pretensão de poder e comando nos planos "territorial, militar ou comercial" e "espiritual e ético", como ressaltado por Mussolini em la dottrina del fascismo (p. 106). A noção transcendente do imperialismo fascista se articulava à de uma guerra sem fim que adquiria na estética a unidade entre o heroísmo do líder, a vitalidade da pátria e a força do povo. A representação dessa unidade permitia ao fascismo converter ação política em violência sagrada contra inimigos e negar qualquer leitura distinta da realidade.

A origem do populismo moderno estaria na contestação pós-fascista da democracia nos primeiros governos de Perón (1946-1955). Finchelstein busca demonstrar continuidades e distinções do populismo em relação ao fascismo e ao que ele denomina de pré-populismos de direita, apresentando 16 características comuns do ideário de regimes populistas de direita e esquerda (p. 127). A principal distinção do populismo diante do fascismo é o seu recurso à semântica da democracia eleitoral como fonte de legitimação. A construção autoritária e antiliberal do populismo moderno rejeita a ditadura, mas herda do fascismo a teologia política que vincula a unidade do povo ao seu líder messiânico contra os inimigos da nação, movendo a "vontade geral" de cada indivíduo para a decisão do líder. 
Ao descrever o fascismo e o populismo nos quadros de uma historiografia global atenta ao Sul, reconhece movimentos autoritários constituídos a partir de uma complexidade formada por distintos traços político-econômicos locais, deslocando-os da dimensão eurocêntrica que os compreende fundamentalmente como formas de Contra-lluminismo. Para o autor, o populismo moderno recusa construir um programa político claro, cabendo projetos, conservadores ou não, intervencionistas ou neoliberais, à esquerda e à direita. Assim, o líder pode definir aliados e inimigos e justificar o autoritarismo, ofertando o autor diversos exemplos históricos (p. 146). Ao apresentar o populismo de forma cosmopolita, Finchelstein argui que a teoria política eurocêntrica designa como "populista", com valoração negativa e pejorativa, na América Latina, ações que são positivamente reconhecidas como social-democratas na Europa.

O autor anota que a escalada global do populismo se associou à ascensão do neoliberalismo, sobretudo após 1989, quando a pauta econômica hegemônica contribuiu para aumentar a concentração de renda e precarizar a legitimação decisória democrática, esmiuçando a ligação entre populismo e neoliberalismo a partir dos anos 1990 na América Latina. Citando Urbinati (2014), aponta a atual afinidade entre populismo e neoliberalismo na Europa e nos Estados Unidos como processo de desfiguração da democracia (p. 206).

Ainda que o método e a narrativa do livro foquem a historiografia, Finchelstein diagnostica os efeitos do populismo contemporâneo, destacando os Estados Unidos da Era Trump. A aliança entre a inflamada retórica anti-imigração e setores religiosos conservadores encontrou no movimento Tea Party o ambiente fértil para se opor às políticas de Obama. A tese de que nos Estados Unidos o sentido do termo populismo entende-se como sinônimo de popular, e ambos associados a causas progressistas e legítimas (p. 175), aponta para o extremo uso xenófobo da noção de "povo norte-americano". Ao mobilizar tal dimensão, o Tea Party e Trump rentabilizaram eleitoralmente o ressentimento contra imigrantes e não brancos. Eleitores trumpistas "gostam de Trump não apesar das suas qualidades antidemocráticas mas precisamente por causa delas" (p. 177). Trump promoveu um "nós contra eles" e reabilitou no imaginário político a luta, ainda que ficcional, contra as elites plutocráticas egoístas e devotas do establishment, ocultando que o próprio integra o grupo a que afirma se opor. Isto ilustraria o paradoxo da nova onda de populismos em reação à crise de representação: recorre-se à semântica da democracia para a defesa de valores antidemocráticos como o pluralismo, enquanto preserva a racionalidade neoliberal da concorrência com outros modelos de desenvolvimento.

No terceiro capítulo, Finchelstein anota ser paradoxal a ditadura embasar o populismo moderno, mas não ser este ditatorial. Apenas então apresenta definições sobre 
ditadura e democracia, afirmando seguir Arato (p. 189), sem as aprofundar, o que é um déficit da obra. Discute se o populismo poderia ser, a um só tempo, anti-institucional, como as ditaduras, e democrático, oferecendo, ao cabo, uma resposta dúbia. O autor entende por anti-institucionalismo a ação de ignorar processos institucionais estabelecidos para praticar violência política, pois, em ditaduras, procedimentos jurídicos poderiam mudar conforme a vontade ditatorial. O populismo moderno estaria baseado teoricamente nas decisões eleitorais majoritárias e, uma vez no poder, reuniria "uma grande medida de política anti-institucional", quando não totalitária, e uma "pequena medida de violência anti-institucional" (p. 202). Sobre o liame populista entre o povo e o líder, cita o suicídio de Vargas como paradigmático (p. 215). O autor, ainda, aborda a classificação de Schmitt de ditaduras comissarial e soberana, sem aprofundá-la (p. 195). O populismo daria relevo à representação democrática, pois a eleição do líder não seria observada como a representação absoluta da vontade do povo, como no fascismo. Quando a vontade do líder populista é confrontada com parâmetros institucionais, há o recurso à participação e às eleições (p. 207), como nos casos de Perón, em 1949, e Chávez, em 2007, sendo ofertados exemplos africanos que combinaram antielitismo e xenofobia.

Finchelstein destaca em Perón a noção de "democracia orgânica", que deveria ser encabeçada por um líder e guia apto a enfrentar a batalha entre o povo e o antipovo (p. 207ss.), o que se refletiu em Gaitán e Betancourt. Mesmo Chávez exibia-se como peronista e considerava os não chavistas não venezuelanos. O autor afirma que Trump tornou-se um Perón estadunidense ao se pôr como "homem forte". Sobre o populismo dos Estados Unidos no pós-1945, argui ser marcado pelo racismo, pelo Tea Party e por Trump (p. 212ss.), mas pouco aborda o histórico racista e populista de outros republicanos e democratas, como G. Wallace, mencionado apenas como um "candidato independente".

Segundo o autor, a mídia foi e é instrumento crucial de propaganda populista. Feitos do líder messiânico são realçados e a mídia independente é vista como uma inimiga elitista. Tal como fascistas, populistas teriam estetizado a política, mas teriam repaginado a propaganda personalista fascista, havendo, no populismo, a coexistência de estratégias midiáticas com processos eleitorais. Essas mídias poderiam estabelecer contato direto com a população, pois não mediados pelos gatekeepers tradicionais, observar a política em termos binários e realçar a política dos costumes. Fazendo da política um espetáculo, constrói-se uma guerra cultural entre o "verdadeiro povo" e os antinacionalistas.

Os dois últimos tópicos são dedicados ao "populismo islâmico" e ao "populismo machista". O autor nega a excepcionalidade do populismo em países de maioria 
muçulmana e não entende haver pretensões universais no "populismo islâmico", apesar de eventuais referências à umma. Já o "populismo machista" incorporaria um ideal de masculinidade e uma visão tradicionalista dos papéis sociais de homens e mulheres (p. 245); mulheres seriam reificadas e gays discriminados. 0 tópico concentra-se nos discursos populistas, mas não apresenta as políticas discriminatórias implementadas.

A obra é bem estruturada e acessível também ao público não acadêmico, mas não discute densamente noções teóricas centrais - como a democracia - e apresenta problemas ao analisar dinâmicas mundiais. Falta-lhe detalhar fenômenos asiáticos e africanos, assim como conexões entre movimentos periféricos e globais, como a tensão entre Estados Unidos e União Soviética no pós-1945 e a força de tais países noutros Estados e na política internacional. Ao basear sua distinção na forma pela qual a violência política é exercida, afirma que populismo não visaria à eliminação física do outro (p. 110 e 194). Contudo, dimensões políticas não nacionais podem ser fonte de exclusão. O "outro" não está somente dentro dos Estados, pois estes promovem guerras e deportações em massa, impedem a entrada de populações consideradas como "inimigas" nacionais, interferem politicamente em outros Estados, além de, internamente, operar visando a exclusão dos "inimigos" do jogo político ou do convívio social. Trata-se, de qualquer modo, de empreitada interdisciplinar de méritos acadêmicos destacados que pode informar, por exemplo, as teorias política e sociológica.

\section{Referências}

FINCHELSTEIN, Federico. Do fascismo ao populismo na história. Lisboa: Edições 70, 2019.

Transatlantic fascism: ideology, violence, and the sacred in Argentina and Italy, 1919-1945. Durham, UK; London: Duke University Press, 2010.

URBINATI, Nadia. Democracy disfigured: opinion, truth, and the people. Cambridge; London: Harvard University Press, 2014. 